\title{
Slurs under quotation
}

\author{
Stefan Rinner $^{1}$ (D) $\cdot$ Alexander Hieke $^{2}$
}

Accepted: 12 August 2021/Published online: 27 August 2021

(C) The Author(s) 2021

\begin{abstract}
Against content theories of slurs, according to which slurs have some kind of derogatory content, Anderson and Lepore have objected that they cannot explain that even slurs under quotation can cause offense. If slurs had some kind of derogatory content, the argument goes, quotation would render this content inert and, thus, quoted slurs should not be offensive. Following this, Anderson and Lepore propose that slurs are offensive because they are prohibited words. In this paper, we will show that, pace Anderson and Lepore, content theories of slurs do provide an explanation of the fact that quoted slurs can cause offense: even under quotation, the explanation goes, the derogatory content of a slur can still be psychologically efficacious. We will go one step further by pointing out that offensiveness is not the only function of slurs, but that slurs can also be used to create and reinforce negative attitudes towards the target group. While content theories can easily explain this by referring to some kind of derogatory content, Anderson and Lepore's prohibitionism will lack a satisfactory explanation of this second function of slurs. Concluding, we will argue that, unlike uses of slurs, uses of quoted slurs normally do not derogate the target group. This will again speak in favor of content theories. Accordingly, uses of quoted slurs are not derogatory because quotation renders the derogatory content inert. Hence, rather than speaking against content theories, quoted slurs speak in their favor.
\end{abstract}

Keywords Slurs · Quotation · Prohibitionism - Content theories of slurs

Stefan Rinner

stefan.rinner@uni-hamburg.de

1 University of Hamburg, Hamburg, Germany

2 University of Salzburg, Salzburg, Austria 


\section{Introduction}

In "Slurring Words", Anderson and Lepore argue that even slurs under quotation "can easily cause offense and alarm" (Anderson and Lepore, 2013a, 37). The example they discuss in most detail is:

(1) 'ni**er' is a term for blacks.

In their follow-up paper "What Did You Call Me? Slurs as Prohibited Words", they provide other examples, e.g. Anderson and Lepore (2013b, 354):

(2) 'Kike' is a derogatory word.

According to Anderson and Lepore, content theories of slurs, which maintain that slurs have some kind of derogatory content, be it semantic (Hom, 2008; Hom and May, 2013), pragmatic (McCready 2010; Whiting, 2007, 2013; Williamson, 2009, 2010), or presuppositional (Cepollaro, 2015; Cepollaro and Stojanovic, 2016; Schlenker 2007), cannot explain this. ${ }^{1}$ If slurs had some kind of derogatory content, the argument goes, quotation would render this content inert and, thus, quoted slurs should not be offensive. ${ }^{2}$ Following this, Anderson and Lepore (2013a, b) propose that (1) and (2) are offensive because "slurs are prohibited words; and, as such, their uses are offensive to whomever these prohibitions matter" (Anderson and Lepore, 2013a, 43).

In this paper, we will discuss Anderson and Lepore's argument regarding quoted slurs in more detail. ${ }^{3}$ In Sect. 2, we will argue that although quoted slurs can cause offense and alarm, the degree of offensiveness is generally seriously diminished, and in the case of mild slurs often even eliminated. Exactly because quotation renders content inert, content theories will have no problems in explaining this. Anderson and Lepore's prohibitionism, on the other hand, will have serious difficulties in explaining this decrease in offensiveness. Furthermore, we will show that, pace Anderson and Lepore, content theories of slurs do provide an explanation of the fact that at least some quoted slurs can cause offense. According to this explanation, even under quotation, the derogatory content of a slur can still be psychologically efficacious.

In Sect. 3, we will go one step further by pointing out that offensiveness is not the only function of slurs, but that slurs can also be used to create and reinforce negative attitudes towards the target group. This will not only be of importance in connection with quoted slurs, but also for discussing slurs in general. For example, we will see that whereas content theories can easily explain that slurs can be used to

\footnotetext{
${ }^{1}$ Here we mainly refer to the theories that are classified as content theories by Anderson and Lepore in their Anderson and Lepore (2013a).

${ }^{2}$ We use the expressions "quoted slurs" and "slurs under quotation" interchangeably with both referring to expression types.

3 Anderson and Lepore present various other arguments against the different versions of content theories. Since these arguments have already been discussed in the literature by the advocates of those theories, we won't discuss them here, but solely concentrate on quoted slurs. Similarly, for other desiderata that an adequate theory of slurs has to fulfill, such as appropriation, embedded uses of slurs etc.
} 
create and reinforce negative attitudes, by referring to some kind of derogatory content, Anderson and Lepore's prohibitionism seems to lack any satisfactory explanation of this fact.

Finally, in Sect. 4, we will argue that, unlike uses of slurs, uses of quoted slurs normally do not derogate the target group. This will again speak in favor of content theories. Accordingly, uses of quoted slurs are not derogatory because quotation renders the derogatory content inert. Hence, rather than speaking against content theories, quoted slurs speak in their favor.

\section{Slurs under quotation}

If we want to formulate Anderson and Lepore's argument against content theories in a logically valid way, it would have the following coarse structure:

1. Slurs under quotation can cause offense.

2. If slurs under quotation can cause offense, then a theory of slurs is correct only if it provides an explanation of this fact.

3. Content theories of slurs do not provide an explanation of the fact that slurs under quotation can cause offense.

Therefore: Content theories of slurs are not correct.

In this section, we will mainly discuss premises 1 and 3 , since we think that premise 1 has to be elaborated in more detail and that premise 3 is false. Premise 2, on the other hand, seems to be self-evident if we interpret 'providing an explanation' very broadly.

Premise 1 is obviously an empirical claim. Thus, strictly speaking, it would have to be confirmed by empirical evidence. Anderson and Lepore do not provide any such evidence. However, we do not dispute the truth of premise 1 if not read as a universal, but rather as an existential statement: there certainly are quoted slurs that can cause offense, i.e. there are uses of quoted slurs where members of the target group are emotionally affected and sometimes even offended. Nevertheless, we think that it is plausible to assume that, in general, uses of quoted slurs are less offensive than uses of the respective unquoted slur. ${ }^{4}$ Again, this is a claim that had to be confirmed empirically. But it is rather obvious that the following uses of quoted slurs are normally less offensive than uses of the respective unquoted slur. ${ }^{5}$

(2) 'Kike' is a derogatory word.

(3) The word 'kike' is an ethnic slur for Jewish people.

(4) When using the word 'kike' instead of 'Jewish people', one is taking the side of anti-Semites.

\footnotetext{
${ }^{4}$ When we speak of the offensiveness of concrete uses of slurs, then we thereby mean the actual offense caused by the token produced.

${ }^{5}$ We would like to thank an anonymous reviewer for pointing this out and for providing the examples (3)-(5).
} 
(5) You should never use the word 'kike' because it is derogatory.

(6) 'negro' is less offensive than the N-word, but it is still a slur.

(7) 'negro' once was a neutral term, but today is considered to be a slur.

For instance, (3) is part of the wikipedia entry for the word 'kike', and (4) is used in Leopold Hess' (2020) paper 'Practices of Slurs Use' in Grazer Philosophische Studien.

In the case of mild slurs, their offensiveness can even be nullified under quotation. For example, Austrians frequently refer to Germans from the north, west and east of Germany with the mild slur 'Piefke', in order to distance themselves culturally from them and to emphasize the Austrians' "superiority". This slur causes little, if any, offense in ordinary usage and is almost never offensive when used under quotation. ${ }^{6}$

We see that premise 1 has to be looked at in a more differentiated manner. In any event, we will argue against premise 3 , i.e. the claim that content theories do not provide an explanation of the fact that quoted slurs can cause offense. Although quotation would render the derogatory content of slurs inert, this very content could still play an important causal role in cognitively or emotionally affecting members of the target group. In general, content can be causally efficacious when an expression is only quoted. For example, an utterance of

(8) 'Aristotle' is the English version of a Greek name.

will in almost every case cause philosophers to think about the well-known ancient Greek philosopher. And an utterance of

'Hitler' is a German surname.

will not only cause thoughts about the infamous Nazi leader and dictator, but in many cases will also cause a negative emotional response, exactly because of the content of the unquoted name. This shows that the content of an expression can be psychologically efficacious even when the expression is only mentioned. Starting from this, content theories can claim that, just like a use of (8) causes hearers to think about Aristotle, a use of (1) or (2) causes them to think about the derogatory content of the respective slur, be it semantic, pragmatic, or presuppositional. This is why even the quoted slurs in (1) and (2) above can still provoke negative emotions among the members of the respective target group and might in some, or even many, cases also cause offense, especially in the case of highly loaded slurs. ${ }^{7}$

This explanation can also be extended to the offensiveness caused by expressions that are phonetically similar to slurs. For example, recently, students of a Chinese class at USC complained that they felt offended by the professor's repeated use of

\footnotetext{
${ }^{6}$ We think that even in cases where a euphemism is available, as it is the case with the N-word, uses of the quoted slur are, in general, less offensive than uses of the respective slur. Hearers could nonetheless be offended by the fact that the speaker chooses the quoted slur over the euphemism.

7 Bolinger (2017) suggests another possible explanation of the offensiveness of quoted slurs that is compatible with a content-based account. According to Bolinger, mentioned uses of slurs manifest the speaker's "disregard for the risk of encouraging derogating uses of the slur" (Bolinger 2017, 452).
} 
the Chinese expression 'nèi ge', a filler word, because of its phonetic similarity to the N-word. ${ }^{8}$ Similarly, the English word 'niggardly' (stingy), which predates the $\mathrm{N}$-word by several centuries and has no etymological relationship to it, has over the last century or so fallen out of use precisely because of its phonetic similarity to the N-word. ${ }^{9}$ Following our explanation of the offensiveness of quoted slurs, this can be explained with the fact that even phonetically similar expressions can cause speakers to think about the derogatory content of the respective slur. However, how exactly a use of a phonetically similar expression or a quoted use causes hearers to think about the expression's original content has to be explained psychologically by means of empirical studies. For the purpose of this paper it is sufficient to point out that quoted uses of an expression can cause hearers to think about its original content. After all, this already explains how the derogatory content of a slur can still be psychologically efficacious if the slur is only mentioned.

Finally, content theories can also explain the decrease in offensiveness between uses of slurs and uses of the respective quoted slur. Exactly because quotation renders the derogatory content inert, the degree of offensiveness is generally seriously diminished, and in the case of mild slurs often even eliminated. It is very unclear though how Anderson and Lepore's prohibitionism can possibly explain the decrease in offensiveness of quoted slurs. Prima facie, quoted slurs are as prohibited as the respective slurs and, thus, according to prohibitionism, they should be equally offensive. Advocates of prohibitionism could try to solve this problem by introducing degrees of prohibitions varying between slurs and their quotations. Anderson and Lepore do indeed offer a short sketch of an explanation of how offensiveness can vary between different slurs or between one and the same slur over time. According to this explanation, the offensiveness of a slur depends on how successful the campaign against its use is, which Anderson and Lepore call silentism (Anderson and Lepore, 2013a, 40-41). In order to extend this explanation to the difference in offensiveness between slurs and quoted slurs, Anderson and Lepore would have to claim that the campaign against the usage of a quoted slur is, in general, more successful than the campaign against the respective slur. However, it seems to be more likely that it is the other way round. Usually, there is much more debate on whether uses of quoted slurs should be prohibited than on the prohibition of the respective unquoted slurs.

Hence, rather than speaking in favor of Anderson and Lepore's prohibitionism, the offensiveness of quoted slurs speaks against it. Moreover, next, we will see that offensiveness is not the only function of slurs. Again, this will speak against prohibitionism, and in favor of content theories.

\footnotetext{
8 https://edition.cnn.com/2020/09/10/us/usc-chinese-professor-racism-intl-hnk-scli/index.html

${ }^{9}$ In his book on the N-word, Kennedy (2002) even describes cases in which people have been fired or taken to court over the use of 'niggardly'.
} 


\section{Beyond offense}

With prohibitionism, Anderson and Lepore primarily want to provide an explanation of the fact that slurs can be used to offend. However, this is by no means their only function. Often slurs are used in the knowledge that no member of the target group is present. Such uses of slurs primarily have the function to create or reinforce negative attitudes towards the target group. Think, for example, of the following situation: a racist leader makes a speech in front of his fellow racists. Assume further that there are only racists present in the room, and that this fact is common knowledge among them. Nevertheless, the racist leader could utter the following sentence in his speech:

(10) As it happens, there live chinks in our country.

Here it is obvious that the slur is not used to offend or insult anyone, since no individual of the target group is present, and this fact is common knowledge among the present persons. But the slur is clearly used in a seriously derogatory and racist way. Such in-group uses of slurs are not uncommon. For example, most uses of slurs for Jewish people in Nazi propaganda had mainly the purpose to create and reinforce anti-Semitic attitudes that should and would lead to increasing discrimination and violence against Jews, to their expulsion or incarceration in concentration camps, and, ultimately, to genocide. Similarly, Tirrell (2012) argues that the massive use of the slur "Iyenzi" (cockroaches) for Tutsis in broadcasts from a Hutu radio station played a crucial role in inciting the genocide of the Tutsis. According to Tirrell, slurs "regularly enact power, incite crimes, and rationalize cruelty" (Tirrell, 2012, 192). ${ }^{10}$

A theory of the semantics and pragmatics of slurs must therefore not only provide an explanation of their offensiveness. It also has to provide an explanation of the fact that slurs can be used to create and reinforce negative attitudes towards the target group, which can in turn lead to increasing discrimination and violence against its members. Content theories have a straightforward explanation of this fact. According to these theories, slurs can be used to create and reinforce negative attitudes towards the target group because they ascribe some kind of derogatory content to its members. Hom and May $(2013,309)$ call this "derogation". ${ }^{11}$ For Hom and May (2013), Hom (2008) slurs make pejorative truth-conditional contributions, such as ought to be subject to higher college admissions standards, excluded from managerial positions ..., because of being slanty-eyed, devious ..., all because of being Chinese in the case of 'Chink'. Other content theories are

\footnotetext{
${ }^{10}$ This can be compared to the distinction between direct and indirect hate speeches (West, 2016, 237-38). Whereas direct hate speeches are aimed at the target group and have the primary function to mentally harm its members, indirect hate speeches are aimed at people who are not part of the target group, with the primary function to incite and reinforce derogatory attitudes towards the members of the group targeted for hate.

11 Hom and May $(2013,309)$ distinguish between offensiveness and derogatoriness in order to explain how slurs can still be offensive under negation, although, according to their semantic theory of slurs, such uses are not derogatory.
} 
presupposition theories and implicature theories. According to the former, sentences containing slurs presuppose derogatory propositions about the target group (Cepollaro 2015; Cepollaro and Stojanovic 2016; Schlenker 2007). For Cepollaro and Stojanovic (2016) the presupposition describes a (derogatory) state of affairs about the target group ("the target group is despicable for being so"), whereas, according to Schlenker (2007), the presupposition expresses how the speaker feels about the target group ("the slur-user despises the target group"). According to implicature theories, on the other hand, the derogatoriness of slurs can be explained by means of Gricean conventional implicatures. For Williamson (2009) these implicatures are derogatory propositions about the target group, whereas, according to Whiting $(2007,2013)$ and McCready $(2010)$, they are non-cognitive attitudes like contempt. The latter are therefore also considered expressivist theories.

It is very unclear how Anderson and Lepore's prohibitionism could possibly explain these facts. Prima facie, advocates of prohibitionism could claim that by willfully violating prohibitions that matter to a socially relevant group, we encourage others to regard the group as lesser or inferior, or to disregard group members' preferences, etc. However, even Anderson and Lepore (2013a, 39) do not maintain that prohibitions of slurs are necessarily enacted by the members of the target group. They mention slurs for infants and severely mentally disabled as counterexamples. In these cases, the prohibitions primarily matter to people who care about the members of the target group, such as their parents, relatives, and friends. Nevertheless, the slurs can be used to create and reinforce negative attitudes towards the target group.

Anderson and Lepore cannot simply respond that for creating and reinforcing negative attitudes towards a socially relevant group it is sufficient to refer to the group with an expression that is in some way or other prohibited. After all, expressions can be prohibited for all kinds of reasons. For example, according to the Académie Française, at least some expressions with foreign origin (especially English) are prohibited, or at least should be avoided, in elevated French. ${ }^{12}$ Similarly, the association Allgemeiner Deutscher Sprachverein wanted to "purify" the German language by eliminating especially expressions with French origin. This is known as German language purism. ${ }^{13}$ Hence, there could, in principle, be expressions for socially relevant groups that are prohibited only because of their foreign origin. However, such expressions would typically neither be slurs nor could they be used to create or reinforce negative attitudes towards the group designated by them. ${ }^{14}$ The question, then, arises what distinguishes slurs from other prohibited

\footnotetext{
${ }^{12}$ For examples see the list of expressions (Termes déconseillés par l'Académie française) on this page: https://www.academie-francaise.fr/le-dictionnaire-la-9e-edition/exemples-de-mots-dorigine-etrangere. We would like to thank an anonymous reviewer for pointing this out.

13 See, e.g., Göttert (2019).

14 Jeshion (2013, fn 38) uses similar examples in order to argue for the claim that being a prohibited expression for a socially relevant group is not sufficient for being a slur. Jeshion's examples are 'rape victim' and 'pregnant virgin' which consist of expressions that were once prohibited. In addition, Whiting (2013) could show that being prohibited is also not a necessary condition for an expression to be a slur. For example, in a deeply racist society the usage of slurs is not prohibited.
} 
expressions for socially relevant groups. As we have seen in connection with slurs for infants and severely mentally disabled, the answer cannot simply be that in the case of slurs the prohibitions matter to the members of the target group.

Anderson and Lepore could argue that despite these difficulties prohibitions can still explain offensiveness. For example, they could point out that hearers to whom the directives of the Académie Française matter may feel offended by utterances that violate those directives. Similarly, people who care about infants and severely mentally disabled may feel offended by the use of the respective slurs, exactly because prohibiting these expressions matters to them. However, at least the offensiveness of slurs also depends on various other factors. For example, there could, in theory, be a mentally very stable target group whose members do not take offense at all by the uses of the respective slur. Nevertheless, they could have a strong interest in its prohibition if they realize that the uses of the slur create and reinforce negative attitudes towards them. In such cases, the members of the target group may also have much more existential worries to care about than the one of being offended. For example, the Jewish people and the Tutsis were probably less worried about being offended (by the Nazis, or Hutu extremists respectively), but rather much more worried about the consequences of the slurs being used to reinforce negative attitudes towards them. Being offended seems to be a luxury they could not allow themselves under these circumstances. Hence, in such circumstances, the slurs could eventually be prohibited if a campaign against their use is successful. And the prohibition would even matter to the members of the target group. However, they would not be offended by the uses of the slurs.

These examples show that prohibitions alone also cannot explain the offensiveness of slurs, but that mental dispositions and existential worries play a crucial role in causing offense. Anderson and Lepore could reply that the same problem arises for content theories. If mental dispositions and existential worries play a crucial role in causing offense, then even an expression with a highly derogatory content may not cause offense in a mentally stable target group. However, being prohibited is not even a necessary condition for an expression to be offensive. For example, in a deeply racist society, the members of a discriminated minority may feel offended by the uses of the respective slurs. But as a minority they may also lack the power to enact a prohibition against their use (Jeshion, 2013, fn 38). Hence, in such a case, the members of the target group would be offended by the uses of the slurs without them being prohibited words. Content theories could again explain this by claiming that the slurs have some kind of derogatory content, even though they may not be prohibited words. ${ }^{15}$

We see that even the offensiveness of slurs cannot be explained by them being prohibited words. Furthermore, it is very likely that apart from non-linguistic factors, such as mental dispositions and existential worries, both the offensiveness of slurs and their role in creating and reinforcing negative attitudes have a single

\footnotetext{
15 Note that we do not claim that there are no slurs that are prohibited words. For instance, the $\mathrm{N}$-word can be considered a typical example of a prohibited word. However, we think to have established that being prohibited is neither necessary nor sufficient for an expression to be a slur, which is why Anderson and Lepore's prohibitionism cannot be correct. We would like to thank an anonymous reviewer for pointing this out.
} 
explanation. Unlike prohibitionism, content theories provide such an explanation, since both the offensiveness of slurs and the fact that slurs can be used to create and reinforce negative attitudes can be explained by them having some kind of derogatory content. ${ }^{16}$ In terms of speech act theory, we can say that, according to content theories, derogation is the illocutionary part of a speech act involving a slur, whereas offensiveness and the creation and reinforcement of negative attitudes belong to its perlocutionary part, which also depends on various other factors. ${ }^{17}$

\section{Slurs under quotation revisited}

We have established that there is a variety of things that can be done with slurs on the perlocutionary level and that, unlike prohibitionism, content theories provide a coherent explanation of these perlocutionary acts. However, non-content theorists could put forward a structurally identical argument against content theories to the one of Anderson and Lepore, presented above, by referring to the illocutionary part of a speech act involving a slur, i.e. derogation:

1. Quoted slurs can be used to derogate the target group.

2. If quoted slurs can be used to derogate the target group, then a theory of slurs is correct only if it provides an explanation of this fact.

3. Content theories of slurs do not provide an explanation of the fact that quoted slurs can be used to derogate the target group.

Therefore: Content theories of slurs are not correct.

We do not want to deny that, under very specific circumstances, utterances of sentences containing quoted slurs can derogate the target group. For example, imagine someone directly addressing a Chinese person by uttering (11) in a provocative manner:

(11) 'chink' originated from the Chinese courtesy ching-ching.

Although (11) is possibly true, its use in this context is highly derogatory and would most probably offend the person addressed. However, the same holds if a white person directly addresses a black person by uttering (12) in a provocative manner:

(12) The N-word is derived from the Latin word 'niger', which just means black.

Since normally uses of (12) do not derogate black people, this has to be explained solely by referring to conversational circumstances, i.e. its reference to a highly

\footnotetext{
${ }^{16}$ Besides offensiveness, the ascription of some kind of derogatory content to the members of the target group also explains other direct harms caused by the uses of the respective slur, such as fear, hypertension, low self-esteem, and even mental illness (Delgado, 1993; Matsuda, 1993).

17 Unlike prohibitionism, content theories also provide a uniform account of slurs (pejoratives) and laudatives. For instance, for Nazis in the German Reich, 'Aryan' was certainly laudatory. Content theories can explain this by claiming that 'Aryan' had some kind of laudatory content. Prohibitionism, on the other hand, needs two theoretical constructs to account for pejoratives and laudatives, which arguably form a natural class. We would like to thank an anonymous reviewer for pointing this out.
} 
derogatory slur combined with pragmatic aspects, such as intonation, facial expression, gestures, who is being addressed by whom, who is present etc. Hence, such an utterance of (12) can be compared to an utterance of (13), with a heavy emphasis on 'Italians'.

\section{(13) Sue loves Italians.}

The fact that such an utterance derogates Italians does not make 'Italian' a pejorative term. Similarly, (12) can be used to derogate black people without the expression 'the $\mathrm{N}$-word' being derogatory.

We think that the same is true of (11). Although (11) can be used to derogate Chinese people, this does not make the quoted slur derogatory. In fact, the explanation of the derogatoriness of the above utterance of (12) also applies to the derogatoriness of the above utterance of (11). After all, the conversational circumstances are virtually the same. ${ }^{18,19}$ Furthermore, just like normal uses of (12) and (13) are not derogatory, normal uses of (11) also do not seem to derogate Chinese people. For example, (11) and (12) are typically used in educational contexts, where derogation almost never is intended. The same holds for (2). ${ }^{20}$ Nevertheless, utterances of (11) and (2) can cause offense and alarm. As we have seen above, content theories can explain this with the fact that the derogatory content of the slur is still psychologically efficacious in (11) and (2), whereas it is neutralized, or at least mitigated, in (12). Thus, we think that the primary reason for introducing euphemisms for strong slurs is not that uses of the respective quoted slur are derogatory, but rather to reduce their offensiveness by mostly blocking the psychological effects of using the quoted slur.

\section{Conclusion}

Let us repeat our findings: Pace Anderson and Lepore, slurs cannot only be used to offend the target group, but they can also be used to create and reinforce negative attitudes towards its members. Thus, a theory of the semantics and pragmatics of slurs also has to provide an explanation of this second function of slurs. Content theories provide a coherent explanation of both the offensiveness of slurs and the fact that slurs can be used to create and reinforce negative attitudes via the illocutionary act of derogation, i.e. the fact that slurs ascribe some kind of derogatory content to the members of the target group. Furthermore, we have seen

\footnotetext{
18 This also explains why the above utterances of (11) and (12) are highly offensive. Hence, the psychological efficaciousness of the derogatory content of 'chink' is not solely responsible for the offensiveness of the above utterance of (11).

19 Similarly, one could argue that utterances of (1) can derogate black people because, at least in certain contexts, they insinuate that it is legitimate to refer to black people with the $\mathrm{N}$-word. However, the same does not seem to hold for (2), where it is made explicit that 'kike' is a derogatory term.

${ }^{20}$ An utterance of ' 'ni**er' is derived from the Latin word 'niger', which just means black', on the other hand, risks being derogatory even in an educational context, because of the availability of a euphemism. However, since this also counts as a conversational circumstance, again the derogatoriness of such an utterance does not necessarily make the quoted slur derogatory.
} 
that content theories provide an explanation of both the offensiveness of quoted slurs and the fact that quoted slurs can normally not be used to derogate the target group. According to these theories, quoted slurs are not derogatory, because quotation renders the derogatory content of the respective slur inert. However, since this content can nevertheless be psychologically efficacious when using the quoted slur, even quoted slurs can cause offense, albeit their offensiveness is generally seriously diminished. According to Anderson and Lepore's prohibitionism, on the other hand, it seems that quoted slurs should be as offensive and derogatory as the respective unquoted slur. Since this is obviously not the case, contrary to Anderson and Lepore's argument, quoted slurs do not make a case against content theories, but, instead, speak in their favor.

Acknowledgements We would like to thank Christopher Gauker for his comments on an earlier draft of this paper and anonymous referees for insightful comments and suggestions.

Funding Open Access funding enabled and organized by Projekt DEAL.

Open Access This article is licensed under a Creative Commons Attribution 4.0 International License, which permits use, sharing, adaptation, distribution and reproduction in any medium or format, as long as you give appropriate credit to the original author(s) and the source, provide a link to the Creative Commons licence, and indicate if changes were made. The images or other third party material in this article are included in the article's Creative Commons licence, unless indicated otherwise in a credit line to the material. If material is not included in the article's Creative Commons licence and your intended use is not permitted by statutory regulation or exceeds the permitted use, you will need to obtain permission directly from the copyright holder. To view a copy of this licence, visit http:// creativecommons.org/licenses/by/4.0/.

\section{References}

Anderson, L., \& Lepore, E. (2013). Slurring words. Noûs, 47(1), 25-48.

Anderson, L., \& Lepore, E. (2013). Did you call me? Slurs as prohibited words: Setting things up. Analytic Philosophy, 54(3), 350-63.

Bolinger, R. J. (2017). The pragmatics of slurs. Noûs, 51(3), 439-62.

Cepollaro, B. (2015). In defence of a presuppositional account of slurs. Language Sciences, 52, 36-45.

Cepollaro, B., \& Stojanovic, I. (2016). Hybrid evaluatives: In defense of a presuppositional account. Grazer Philosophische Studien, 93(3), 458-88.

Delgado, R. (1993). Words that wound: A tort action for racial insults, epithets and name? Calling. In M. J. Matsuda, C. R. Lawrence III, R. Delgado, and K. Williams Crenshaw (eds.), Words that wound: Critical race theory, assaultive speech and the first amendment, (pp. 89-110). Westview.

Göttert, K.-H. (2019). Die Sprachreiniger. Der Kampf gegen Fremdwörter und der deutsche Nationalismus. Ullstein.

Hess, L. (2020). Practices of slur use. Grazer Philosophische Studien, 97(1), 86-105.

Hom, C. (2008). The semantics of racial epithets. Journal of Philosophy, 105, 416-40.

Hom, C., \& May, R. (2013). Moral and semantic innocence. Analytic Philosophy, 54, 293-313.

Jeshion, R. (2013). Expressivism and the offensiveness of slurs. Philosophical Perspectives, 27, 231-59.

Kennedy, R. (2002). Nigger: The strange career of a troublesome word. Pantheon Books.

Matsuda, M. J. (1993). Public response to racist speech. In M. J. Matsuda, C. R. Lawrence III., R. Delgado, \& K. W. Crenshaw (Eds.), Words that wound: Critical race theory, assaultive speech and the first amendment (pp. 17-52). Westview.

McCready, E. (2010). Varieties of conventional implicature. Semantics and Pragmatics, 3(8), 1-57.

Schlenker, P. (2007). Expressive presuppositions. Theoretical Linguistics, 33(2), 237-45. 
Tirrell, L. (2012). Genocidal language games. In I. Maitra \& M. K. McGowan (Eds.), Speech and harm: Controversies over free speech (pp. 222-248). Oxford University Press.

West, C. (2016). Freedom of expression and derogatory words. In K. Lippert-Rasmussen, K. Brownlee, \& D. Coady (Eds.), A companion to applied philosopy (pp. 236-52). Wiley.

Whiting, D. (2007). Inferentialism, representationalism and derogatory words. International Journal of Philosophical Studies, 15(2), 191-205.

Whiting, D. (2013). It's not what you said, it's the way you said it: Slurs and conventional implicature. Analytic Philosophy, 54(3), 364-77.

Williamson, T. (2009). Reference, inference and the semantics of pejoratives. In J. Almog \& P. Leonardi (Eds.), The philosophy of David Kaplan (pp. 137-58). Oxford University Press.

Publisher's Note Springer Nature remains neutral with regard to jurisdictional claims in published maps and institutional affiliations. 